\title{
History of health technology assessment: Spain
}

\author{
Laura Sampietro-Colom \\ Hospital Clinic \\ Jose Asua \\ Basque Office for Health Technology Assessment (Osteba) \\ Eduardo Briones \\ Valme University Hospital \\ Jordi Gol \\ Spanish Agency for Health Technology Assessment (AETS) \\ and the AuNETS Group
}

Objectives: The aim of this study was to describe the characteristics of the introduction and diffusion of health technology assessment (HTA) in Spain.

Methods: A survey to summarize the evolution of HTA was sent to representatives of different HTA initiatives in Spain.

Results: HTA was introduced in the late 1980s. The main factors were the trend to an increase in healthcare expenditure, concerns regarding efficiency in providing health care, as well as in the level of rationality introducing high technology. Spain has direct (i.e., regulation) and indirect (i.e., payment systems, evidence-based programs, HTA) mechanisms to control health technologies. A recent high priority regulation has established the need of HTA to decide the introduction of a new health technology in the lists of public healthcare coverage, although similar regulations existed in the past and were scarcely implemented. HTA initiatives started at the regional government level. Its introduction followed a progressive pattern among regions. In the beginning, resources were scarce and expertise limited, with work done at intramural level. With time, expertise increase, and promotion of commissioned work was implemented. HTA knowledge transfer in the healthcare system has been carried out through courses, publications, and commissioned research. Currently, there are seven HTA units/agencies, which coordinate their work. Conclusions: HTA in Spain is in its maturity. Facing the unavoidable change of health care environment over time, HTA is also evolving and, currently, there is a trend to broaden the areas of influence of HTA by devolving capacity to hospitals and applying principles to very early phases of health technology development, under the umbrella of regional HTA units/agencies. However, there are two main challenges ahead. One is to have a real impact at the highest level of healthcare policy coordination among Spanish regions, which is done at the Central Ministry of Health. The other is to avoid the influence of political waves in the level of recognition of HTA at the policy decision-making level and to have an adequate and stable funding of HTA initiatives.

Keywords: Health technology assessment, Spain, Regions, History, Regulation, Health care policy

\section{THE SPANISH HEALTHCARE SYSTEM}

Spain is located in the Iberian Peninsula, in the southwest of Europe and includes in its territory Canary Islands, Ceuta, and Melilla. It is territorially organized into seventeen autonomous regions. Health and healthcare in Spain is stated as a right by the Spanish Constitution, passed in 1978, health being considered both a private and a public good. The "Ley 
General de Sanidad" (General Health Act, LGS) of 1986 consolidates the "Sistema Nacional de Salud" (National Health System, NHS), with universal coverage, free at the point of delivery. The LGS allowed each autonomous region in Spain to develop its own healthcare service, using healthcare resources available within its domain, regardless of ownership. In practice, there had been a political consensus on keeping the system as such in the past 30 years, including equity as a core value. Since 1981, power on the financing, planning, and management of health and health care have been progressively decentralized to each autonomous region. Starting in 1981 in Catalonia, this process ended on the first of January 2002. Nowadays, the Spanish Central Ministry of Health has as its tasks mainly coordinating NHS functions, development of laws that apply to all the country, and international representation.

Funding of health and health care come mainly from taxes; with the exception of small co-payments for ambulatory drugs and out-of-pocket payments for OTC and dentistry. Eighteen percent of the Spanish population has double coverage (i.e., they have a private healthcare insurance) (13). Physicians working at public primary care and hospital care are paid by salaries. Some autonomous regions have a mixed system of fixed and variable salaries, which is envisioned as a means to encourage quality and productivity. The variable portion of the salaries could come from the achievement of objectives or the development of the so-called professional career.

\section{MECHANISMS TO RATIONALIZE HEALTHCARE PRACTICE AND HEALTH TECHNOLOGIES}

As in other developed countries, Spain has used several mechanisms to promote the introduction and diffusion of those practices and health technologies of proven added value while stopping the adoption of those that do not bring appropriate benefits and costs relationships. These mechanisms are direct and indirect, and are represented through specific legislation, different financing or payment methods, and research strategies. Table 1 shows these mechanisms.

Direct mechanisms are mainly represented by laws and other regulations. The first attempt to introduce a regulation on health technology assessment (HTA) in Spain was done by the Central Ministry of Health in 1995 (24), when an explicit regulation from the central government, that should be followed by all regions, was issued linking the introduction of new procedures and medical equipment to the assessment of safety, efficacy, and efficiency. It also allowed temporary approval for introduction of new technologies that were under clinical trials. Public coverage of new technologies, specifically equipment and procedures, takes into account their efficacy, efficiency, clinical safety, utility, and availability of healthcare alternatives, and their relevance to the protection of minorities and social needs (28).
Table 1. Mechanisms Used in Spain to Control Health Technologies

\begin{tabular}{|c|c|}
\hline Direct mechanisms & Indirect mechanisms \\
\hline $\begin{array}{l}\text { - Medical device regulation } \\
\text { (1996) (CE label) }\end{array}$ & - \% GDP devoted to health care \\
\hline $\begin{array}{c}\text { - Health Care System Unity \& } \\
\text { Quality Act (2003) }\end{array}$ & $\begin{array}{l}\text { - Autonomous regions' health } \\
\text { budget }\end{array}$ \\
\hline - Drug Act (2006) & $\begin{array}{l}\text { - Healthcare center's budget } \\
\text { (for hospital and for } \\
\text { primary care) }\end{array}$ \\
\hline $\begin{array}{l}\text { - Health Care Services } \\
\quad \text { Coverage Regulation (2006) }\end{array}$ & $\begin{array}{l}\text { - HTA agencies /units at } \\
\text { Regional level } \\
\text { - Evidence-based and HTA } \\
\text { initiatives in hospitals } \\
\text { (GENESIS Project, HTA } \\
\text { units) and in Primary } \\
\text { Care (CANM) }\end{array}$ \\
\hline
\end{tabular}

CE,; GDP, gross domestic product; HTA, health technology assessment;

Currently in Spain, there are four major active regulations addressed to rationalize and control health technologies and clinical practice in general. The oldest is the transposition of the EU Directive on Medical Devices, which requires evidence on safety and efficacy for market approval (24); however, other considerations necessary to really assess the value of these products are not addressed in this legislation. Three more recent regulations embrace the HTA requirements to introduce and diffuse healthcare technologies in clinical practice. Regarding drugs, the recent Law in Medicines established, as mandatory, that primary healthcare areas (in each autonomous region) have to have a unit devoted to establish information systems for drug management, including information on safety, efficacy, effectiveness, and efficiency of the use of drugs; to deliver appropriate information and education to physicians on the properties of specific drugs; and to develop guidelines and protocols for drug prescription. Additionally, this law states that hospital drugs and services have to collaborate in hospital committees for the selection and evidence-based evaluation of drugs and their use (23). The other two regulations apply to any innovative healthcare technology and clinical practice. Both the Health Care System Unity and Quality Act (2003) (22) and the Health Care Service Coverage Regulation (2006) (26) state that "the new techniques, technologies and procedures have to go through an evaluation process before their introduction to the National Health System. This evaluation has to be performed by the Spanish Agency for Health Technology Assessment in collaboration with the agencies from regional governments." Criteria for public coverage are as follows: to show an effective contribution to the prevention, diagnosis, treatment of diseases, to maintain or improve life expectancy, to promote self-autonomy or to eliminate or decrease pain and suffering; to show an improvement in safety, efficacy, effectiveness, efficiency, or utility compared with currently available alternatives; and to comply with the current legislation if drugs or medical devices are used in the process of care. 
Spain devotes 8.3 percent gross domestic product to health care. This figure is below the average expenditure of the Organisation for Economic Co-operation and Development (OECD) countries (39). However, although this is considered a mechanism to somehow control indirectly the costs of healthcare technologies, the expense in healthcare technologies (excluding drugs) is one of the highest among the OECD countries (8.2 percent of the healthcare expense) after Germany (5). The drug expenditure represents 23.1 percent of the total healthcare cost, the highest among the OECD countries (followed by Portugal with a 17.2 percent) (39). The distribution of the annual budget to the regions, which includes the healthcare budget, from the central Ministry of Health is another way to control practice and hospital care.

Regarding hospitals, public health care centers have their own budget settled yearly by the Department of Health of each region. These budgets are also a tool to rationalize the introduction and diffusion of technologies. Each hospital has the so-called pharmaco-therapeutic commission. Most of these commissions, especially those in teaching and high technology hospitals, are in charge to advise the purchase of big ticket drugs. They assess the added value of drug innovations approved by the Spanish Medicines Evaluation Agency by means of a review of the evidence regarding its safety, efficacy, and cost. The steady increase of the expenses in drugs for hospital prescription has led to the development of the Genesis Project. This project is being led by the Spanish Society for Hospital Drugs with the aims of standardizing a methodology for the evaluation of the added value of hospital drug innovations approved by the Spanish Medicines Evaluation Agency; and to validate the methodology by the participant hospitals (reproductibility and applicability). The methodology used is based in the systematic review of evidence of drugs. Currently, there are thirty-four hospitals (mainly teaching hospitals) collaborating from eleven autonomous regions (20). In the area of drugs, at the primary care level an initiative to assess and control the added value of innovative drugs has been established as a coordinated project among five autonomous regions (Aragón, Andalusia, Catalonia, Navarra, Basque Country). This project, called the "mixed committee for the evaluation of new drugs" (CANM) is addressed to primary care physicians who cover 50 percent of the Spanish population (20). For equipment and medical devices, no similar procedures are formally established. However, the existence and promotion of the role of HTA agencies and units, as well as the promotion of evidencebased initiatives, are helping the sound introduction of health technologies and are another mechanism used to rationalize clinical practice.

\section{INTRODUCTION AND EVOLUTION OF HEALTH TECHNOLOGY ASSESSMENT IN SPAIN}

HTA initially appeared during transition times. On one side, the transfer of health care to the autonomous governments was gaining momentum, and on the other, the promulgation and latter development of LGS established health care as basically a public affair. Otherwise the management of the social security of these times was ruled by strict and narrow procedures, within a somewhat heavy bureaucratic tradition and a culture not prone to policy analyses or formulations, or indeed debate. In consequence, it has taken too much time and effort to develop double accounting systems for hospitals (i.e., diagnosis-related group/conjunto míni- mo básico de datos [CMBD] based) or proper process information data management. Part of the problem was the relative lackoften unrecognized - of properly trained senior staff and managers (45).

Several benefits were expected from the process of transferring services to the autonomous communities, including increased accountability, community development and involvement, sophistication of the policy processes (and its politics!), and some spur of creativity: fresh approaches, more room for creativity, what elsewhere has been called the emulation factor. Many examples of that can be found, and indeed HTA is one of them. There were arguably three structural factors interacting at that time. Cost control was becoming a new issue for health care, in Spain and elsewhere. The pace of technological innovation was accelerating. New and much more expensive drugs (cancer, immunosuppressant, drugs for lowering lipid levels), along with sophisticated and costly procedures, were becoming generalized (coronary artery bypass graft surgery). A new generation of expensive equipment was emerging, in the wake of computed tomography scanning (i.e., magnetic resonance and positron emission tomography were already on the horizon). The rigidity of the bureaucratic processes did not help orderly adoption of many innovations by institutions, but there was a substantial pressure for it better adoption, from public opinion, from the vendors, and from the professionals. Occasionally some independent facilities were established for a specific service (like imaging or dialysis) and pressured the public administrations to contract out the services. Facing this healthcare atmosphere, HTA meant the development of a reserve of analytic skill either in house or close by, and was given a try. At that time, the main concern was mostly technology adoption, as elsewhere (44).

Therefore, several reasons fertilized the Spanish policy arena to look for structured approaches that help making sound decisions on adoption and diffusion of health technologies, such us HTA. One of them was the trend to an annual increase in per capita healthcare spending, which was attributed to the introduction of expensive technologies and the increase in its intensity of use, and a reduction in efficiency in providing health care (i.e., increased costs without a corresponding increase in effectiveness). Another reason was a widening gap between consumers' rising expectations, the pressure from press and from some lobbying professional associations or particular groups of physicians, and the availability of health systems to deliver using wise 
criteria. Finally, the traditional use of clinicians as consultants to advise decisions on technologies was questioned, due to the usual lack of objectivity (most were champions on their clinical areas, which sometimes led to an excessive enthusiasm regarding new technologies), stimulated attempts to look for a more systematic and objective approaches to get information and advice on the best way to allocate scarce resources.

All the mentioned limitations and uncertainties were present in the healthcare policy field, but there were no ideas or initiatives from the top level policy makers to solve the situation. However, isolated professionals started to lobbying health authorities letting them know the existence of a discipline that could provide the information needed to take sound decisions regarding the adoption and diffusion of health technologies (i.e., HTA).

To understand the characteristics of the introduction and dissemination of HTA through Spain, it is necessary to take into account that the country has followed a progressive decentralization power of healthcare financing, planning, and management from the 1980s to the end of the 20th century, as mentioned above. During those 20 years, decentralization was only made to seven autonomous regions (Catalonia, Basque Country, Andalusia, Canary Island, Galicia, Valencia, and Navarra), and it was progressive. The remaining ten autonomous regions were under the power of the Central Ministry of Health until the year 2002, when all the powers on health and health care were transferred to autonomous regions. This explains why the HTA units have evolved differently in time and the fact that currently there are seven structured HTA agencies in Spain.

The first institutional initiative for the promotion of a rational introduction and diffusion of HT dates from 1984 when an Advisory Board on High Technology was created, with clinicians from different specialties, aimed to inform about the usefulness of high health technology (28). However, knowledge-based policy making, using HTA criteria, was first formally introduced in Spain in 1988 in Catalonia (one of the autonomous regions of Spain), when a clinician, with knowledge in HTA, was hired by the regional government to take part in an already existing Advisory Board of clinicians advising the Catalan Ministry of Health on investments in high technology (i.e., expensive and sophisticated healthcare technologies) (18). Members of this Advisory Board were physicians from different clinical specialties, and their mission was to furnish information about the usefulness of high health technology. With time, the evolving scientific evidence and the need to undertake a more comprehensive analysis, where economic, social, and ethical criteria were also included, led to the creation in 1991 of the Catalan Office for Health Technology Assessment (COHTA) as an administrative unit inside the Catalan Ministry of Health (19). At the same time, other autonomous regions started to get interested and involved in HTA, and started to plan the possibility to create HTA units.
In 1990, the promoters of the Technology Assessment project of the Comett-ASSESS European initiative (a framework of educational institutions and enterprises) were seeking partners in Spain. The main activity ended up being a week-long residential course on technology assessment in Malaga in 1992, which had some visibility, whose faculty included international leaders of the field and was attended by senior staff and industry (44). A few months latter, the Basque government in its senior management continuing education program included a 2-day residents session. Later that year, in December 1991, a 2-day seminar was also held in Seville (Andalusia) on HTA as a part of the health and scientific program of the universal exhibition Expo 92. There were more than twenty speakers, including regional and national officials, top clinicians and researchers, and representatives from WHO Europe. It was probably the first institutional initiative in the Andalusia region on HTA, although some preliminary ideas were included in previous health planning documents. In that seminar, the possibility of establishing an office or agency was discussed and actually, an offer to establish a national agency located in the island of La Cartuja in Seville was formally made by the Andalusia Health Minister and the presentations and conclusions of the working groups were published (9).

The second HTA unit was established in the Basque Country (Osteba) in June of 1992, as an administrative unit within the Directorate of Health Organisation and Evaluation of the Basque Department of Health. From its beginning, Osteba has worked closely with the Epidemiology Research Unit and the Drug Information center of the Basque Department of Health. It also has advisory scientific committees that provide support to their work (28). One of the key actions conducted during the early days was the visit to the established agency in Catalonia, as well as some of the most important international agencies of the time. Some of the most relevant initial tasks were to establish links with the existing HTA agencies and the creation of an HTA report library (bearing in mind that, at that time, the Internet essentially did not exist in Spain) and the development of a documentation database.

The third agency to be created was at the Ministry of Health, that is, at the central administration, and its development process took some time. First, a unit of deputy-direction rank was created within the General Direction of Health Planning in the late eighties. This unit helped to rationalize several initiatives within the Ministry, but itself and its own General Direction were reorganized several times, with changes of leadership. Nevertheless, it gave saliency to the issue of technology and the need of a proper approach. There were times of innovation for both the communities and for the central administration, otherwise heavily involved in the transfer of services (related or not related with health care) to the autonomous regions, which inevitably had elements of power politics. In 1992, for the first time the international government-related HTA institutions met in a closed session in Vancouver at the annual meeting of the previous 
International Society for Technology Assessment in Health Care (ISTAHC). The Catalan Agency (CAHTA), the Basque Agency (Osteba), and the Central Spanish Ministry of Health were participants at this meeting. That put HTA slightly higher on the central Spanish Ministry's agenda, so to speak. A scheme by the promoters of HTA within the Ministry was put forward. Additionally, the board of ISTAHC was invited to hold its winter meeting in Madrid, and make of it an opportunity to gain saliency for the HTA cause while holding a senior seminar. That was done in 1993, the seminar went well and the notion was sold at the central level. In 1994, after careful consideration, the central Ministry of Health decided to create a unit of HTA (i.e., Spanish Agency for Health Technology Assessment [AETS]) as a branch of the Carlos III Public Health Institute (ISCIII), an organization devoted mainly to fund, manage, and perform healthcare research (28). From its beginning, AETS profited from complementary scientific resources and know-how available in other units of the ISCIII, such us the Epidemiology National Centre, the National School of Public Health Laboratories. Further expertise was being obtained through collaboration with health professionals (4).

After the successful meeting in 1991, the idea to establish an HTA office or agency in Andalusia was considered by the Andalusian Health Department and was included in the Health Plan in 1993, which mentioned the promotion of the appropriate use of health technologies. At that time, some research groups, such as GRECA in Valme Hospital, were in contact with RAND-UCLA and evidence-based medicine (EBM) groups, also participating in ISTAHC meetings. The establishment of the Andalusian School of Public Health and the development of health services research groups was also influential. Although activities in HTA at the regional government were carried out from 1993, it was not until 1996 that the Andalusian Agency for Health Technology Assessment (AETSA) was officially created (36).

Institutional activities on HTA were initially developed by the regional government of the Canary Islands in 1993, by means of an HTA Unit (Health Technology Assessment Unit of Canary Island [SESCS]) linked to the Department of Health Planning and Evaluation at the Directorate of the Canary Islands Health Service. The starting motivation was the commitment with a planning process in the region focused in health priorities and guided by the scientific evidence of effectiveness and cost-effectiveness to prioritize the selection of healthcare interventions for the Health Plan of the Canary Islands. The initial composition of the unit was an epidemiologist and two health economists.

As seen above, most of the Agencies started as a unit inside the Ministry of Health (central or regional). These units were composed of the Director and a few scientists with a background in epidemiology, health economics, and biostatistics. Due to the lack of a formal teaching program in HTA in Spain, most of the professionals working in these units learned the HTA discipline from reading, attending
ISTAHC meetings, or by taking courses performed outside the country (12). Experiences and projects from countries abroad were also useful. Most of the work was performed intramurally, by the professionals hired in the unit, with collaboration from external clinicians. From the very early stages, training and methodological manuals were developed by most of the units/agencies. There was also a strong and active commitment to spread the methods of HTA and health services research among health professionals in the region to improve understanding of HTA needs and create a "culture" of evaluation in the healthcare field. Funding was also an important issue faced by agencies at the beginning. Most of them received minimal funds from their Regional Ministry of Health (mainly devoted to structural expenses), so they were forced to look for external funds such us presenting projects in competitive national research calls.

Initially, an informal relationship between the units in Spain was present. There were visits to one or another HTA unit in the country and exchange of information, knowledge about methods and products developed, as well as debate on policy activities to recommend in the HTA field. Coordination and avoiding duplication was considered an important issue from the beginning, although this issue was not always resolved. In the early stages, some specific topics were addressed by several units/agencies, which created duplications and a sense of lack of efficiency in the investment of resources devoted to HTA. With time, this situation has disappeared, as will be mentioned below.

Another national initiative was the creation in 1993 of the Spanish Society for HTA, that is, AEETS. The Board of AEETS was made by the directors of the different Spanish HTA agencies/units. Its main task has been until now to organize seminars and scientific meetings every 2 years. From its creation, seven initiatives have been carried out ranging from methodological perspectives to policy issues (e.g., HTA, science, or politics?; EBM, HTA, and clinical practice; evaluation of the impact of the health interventions [outcomes]; evaluation of the health organizations, pending subject?; HTA and priority setting; HTA and their use, integrating the clinicians and citizens perspectives; regulation, innovation, and HTA).

The rigorous work performed by the units, or initiatives not still consolidated as HTA units, and the fact that policy makers believed that the knowledge gap regarding new technologies was diminished when recommendations from HTA units were available encouraged the consolidation, the growth of the units, or the change in their legal status. In 1994, the COHTA was moved to a new legal status with the creation of the Catalan Agency for Health Technology Assessment (CAHTA). CAHTA was created as a nonfor-profit public company affiliated with the Catalan health service, being able to broaden its scope of influence (public/private, national/international), to improve project management, and to diversify its services and products, while preserving objectivity and rigor. This new legal status led, 
in 1996, to the achievement of 15 percent of its funds from third parties (28). In 1996, AETSA was created throughout the publication of Decree 318/1996 by the Andalusian government. AETSA was formed as part of the structure of the Regional Ministry of Health, and has a fifteen-member Scientific Advisory Committee, composed of clinical specialists, researchers, economists, and other experts, and a small staff. In the Canary Islands, the HTA unit grew and was transformed to an HTA service, with more professionals and duties. In 2000, AETSA was integrated into the new General Secretariat of Quality and Efficiency (SGCE) and was commissioned to provide scientific support to the many groups involved in this new process to establish the most appropriate approach to the treatment of patients with specific healthcare problems.

The rising interest of HTA in policy and scientific areas during the first years of the 1990s decade, led to the organization in Barcelona of the International Annual Meeting of old ISTAHC in 1997 (33). This was a historical turning point in the history of HTA in Spain. This meeting showed the world the good health of HTA in Spain and its professional and rigorous way of working. Additionally, it helped to show Spanish policy makers the existence of a strong HTA international community, which serves their respective governments.

One year latter, in 1998, the autonomous region of Galicia started related activities in HTA, when an advisory Committee on HTA was created in the region. That same year, an administrative unit was created within the regional government to inform the decision-making process and give decision makers access to the best available scientific evidence. In 1999, the Galician Agency for Health Technology Assessment (Avalia-t) was officially established, as part of this administrative unit. It still maintains this structure. The main barrier to the establishment of the Galician HTA agency was the difficulty to gather trained staff. The first initiative to solve this was to organize a Masters in Health Technology Assessment, and several specialized courses to train new Avalia-t staff, given by nationally recognized experts. Without doubt, this starting point, giving emphasis to the training and developing a solid high quality methodology, has been one of the strengths of this organization. Funding was another difficulty for the establishment of Avalia-t. At the beginning, it was partly resolved with external funding from various HTA research projects; this situation continues up to now.

Galicia was the first Spanish region to officially regulate the introduction of new technologies with a specific regulation in 2003 (11). From 2007, reports advising the introduction of health technology in the region from Avalia-t are mandatory. The adoption of the conclusion and recommendations by decision makers are not mandatory, however (10). In the autonomous region of the Basque Country, to regulate the introduction of new technologies, on November 12, 2004, the Basque Official Journal published the Procedure for the Incorporation of Health Technologies in the Basque health- care system. The regulation has been the way to structure the entire process for the management of health innovation in the Basque Country. Worth mentioning is that, in the year 2000, the CAHTA in Catalonia proposed a similar system, but it was never followed due to political changes.

Looking at their own information needs, and the success from those regions with HTA initiatives, other autonomous regions followed the example and created their own HTA units. The unit for HTA (i.e., UETS) was established in 2003 in the autonomous region of Madrid. This unit belongs to the Laín Entralgo Agency, a nonprofit public agency of education, health research, and studies supported by the regional Ministry of Health of the Region of the Madrid. The Agency was created as an organization of public right, with its own legal personality and legal capacity, assigned to the Regional Ministry of Health. Since its inception, this unit has taken an active part in several international and national HTA projects.

The expertise of professionals working in HTA units/agencies also evolved with time. The experience reached on the discipline and the growth and change of demand characteristics from policy makers implemented the multidisciplinary work (intra- and extramural) as well as the commission of work to professionals in the healthcare field. The increase in experience led to more elaborated and sophisticated HTA reports. Additionally, the demands from clinicians and other public health professionals to learn about HTA resulted in the production of courses, workshops, books (35), and on-line postgraduate courses $(1 ; 2)$, in which professionals from different Spanish units/agencies collaborate. Additionally, courses in HTA were introduced at the pregraduate level in medical school in the year 2000 in Catalonia.

The growing and changing demands from HTA information led to commissioning HTA work under research contract. In 1996, an agreement between CAHTA and the Catalan Health Service, the organization in charge of funding health care in Catalonia, led to funding an evaluation-oriented research oriented to answer specific uncertainties related to healthcare technologies in Catalonia (28). This initiative was followed by Osteba, and considered by other HTA units. Although this initiative on evaluative research was quite new as an explicit policy rule, previous initiatives existed in Spain introducing emerging technologies with public financing through clinical trials (27).

Although as mentioned above, initial collaboration among Spanish agencies was informal, and not related to specific projects, at the national level, with the progressive involvement of the agencies/units in the international arena, formal cooperation among Spanish agencies/units was fostered. International cooperation and collaboration in HTA were seen as a key activity by units/agencies from the beginning. The pioneering agencies/units were members of the International Network of Health Technology Assessment (INAHTA) from its creation. Catalonia and the Basque Country were also founding members. Additionally, Spanish HTA 
agencies were active participants of the first common project from the INAHTA, being responsible for the development of one of the sections (29). At the European level, Spanish agencies have also been very active in all the initiatives developed from the beginning (EUROASSESS [7], ECHTA [34], EuroScan [15]) to the most recent initiative (EUnetHTA) (14).

One of the common concerns for the HTA units/agencies during all these years has been the lack of appropriate resources, both in experienced professionals and in economic funds, to carry out HTA projects properly and with high standards of quality. This claim was raised by all the units/agencies to the Central Ministry of Health and, by the year 2006 the "The Quality Plan for the Spanish National Health Service" was created (38). This plan has several areas of action, one of them being clinical excellence. Inside this item, a specific action regarding HTA is being promoted. This is the frame to establish formal contracts between the agencies/units for HTA and the central government, which creates a formal network of HTA inside the National Health Service. The central government has devoted 45 million euros, for the period 2006-08, to strengthen the work of HTA agencies in Spain as well as to promote specific initiatives related to HTA (43). One of these initiatives is to implement original research using HTA methods and criteria, through a call for research (25). The other, is to devote funds in the education of healthcare professionals in HTA (21).

This initiative to implement HTA in Spain through the "The Quality Plan for the Spanish National Health Service," has promoted the creation of the virtual network of Spanish agencies called AUnETS (6). This new collaboration has led to a move from informal contacts to a more structured and project-specific debate. Duplication of efforts has been minimized and a higher quality of HTA reports has been seen.

In the year 2007, the IV Annual Meeting of the International Scientific Society on Health Technology Assessment (HTAi) was carried out in Barcelona (30). Ten years after the first international meeting, this meeting would show the world the maturity of HTA in Spain and its coordinated approach. Although the meeting was organized by the Catalan Ministry of Health, all Spanish agencies collaborated directly, either in the advisory committee (all the directors of the agencies) or the scientific local organizing committee. During the meeting, the AUnETS network was present in the exhibition space, showing the products developed for each HTA agency.

Currently, there are several initiatives that point out a new evolution of HTA in Spain. As in other countries around the world, HTA is starting to be devolved from governmentallinked HTA units/agencies to hospitals. These initiatives come from both professionals working in hospitals that understand the need to use HTA in the decisions to introduce new technologies into the hospitals and from units/agencies that understand the relevance of hospitals as the first line entrance for healthcare technologies. Up to now, there have been a few formal initiatives, which have different formats and scopes. One of these initiatives has the form of Hospital Technology Committees, which includes clinicians from different specialty and professionals from the staff of the hospital, that meet from time to time to assess and discuss the feasibility of introducing new technologies (e.g., Hospital Valle Hebron, Barcelona; Hospital Miguel Servet, Zaragoza). An interesting instrument is the guideline for the acquisition of new technologies (GANT) developed in Andalusia, aimed at facilitating decision making in public hospitals. It includes concepts and tools of HTA, a questionnaire for applicants, a checklist with basic requirements, and recommendations to classify the proposals and for decision making on introduction of new technologies and investments. It is perceived as a useful tool in most hospitals of Andalusia (3). One of these hospitals has professional expertise in HTA to help and support the development of specific HTA performed by multidisciplinary teams and promoted by the Quality Directorate of the Hospital (Hospital Valme, Sevilla, Andalusia). Finally, another approach to decentralization and broadening the scope of HTA in hospitals, specifically in teaching hospitals, is the creation of a specific unit of HTA for assessing innovations (i.e., technologies coming from $R \& D+i$ process inside the hospital and emerging technologies coming from outside the hospital). The criteria used for assessing technologies are applied (qualitatively for $R \& D+i$ ) at early stages of development to forecast the potential future success of the product and to help the design of research projects aimed to answer the information that policy makers will need to have to answer the information that policy makers will need to have to make future decisions on its funding (Hospital Clinic, Barcelona) mini-HTA questionnaires are also used. This activity is promoted from the Innovation Directorate of the hospital through its research foundation (17).

Another interesting move of HTA in Spain is its growing interest and adoption by industry. Internationally, drug companies have been mainly the companies to become involved in HTA, acknowledging the need to gather the appropriate data for governmental HTA units/agencies to analyze and make recommendations (one example of this is the policy forum, an area of open debate between industry, governments, and HTA experts, under HTAi (31). However, in Spain, the most active industry in this area is the one addressed to medical devices. Somehow emulating the initiative of the HTAi, in Spain the Federation of Medical Device Industry has also recently created the "Technology and Health Foundation" (16). Its aim is to promote the research and assessment of new technologies and to create space for a dialog with Spanish HTA agencies. Although this is an initiative that aims to emulate the Policy Forum from HTAi, its main difference is that it is promoted and funded by industry and not by a neutral body, such us a scientific and professional society, at the international level. 


\section{DISCUSSION}

HTA in Spain is now in its maturity, although the creation and development of organizations and formal activities in the HTA field have occurred at different speeds among the Spanish autonomous regions.

Health technologies assessed by agencies have been traditionally equipment, medical devices, and surgical and medical procedures, mainly because of the lack of formal regulations that ensured their safety and efficacy in the past. Additionally, the existence of drug assessment units, and a stricter regulation on the approval of drugs, inside the central Ministry of Health have precluded the generalized assessment of drugs by HTA agencies. However, some agencies such us CAHTA $(29 ; 40)$ and Osteba (29) have been involved in drug assessment in the past. Although regulation on drugs exists in Spain, this is mainly addressed to market purposes, leaving considerations on effectiveness, cost, cost-opportunity, and social issues lacking. However, with the new act on drugs (23), there is the wish to create a "value commission" for which the added value of new drugs will be assessed using HTA approaches. This Commission will have representatives from different autonomous regions, and the advice of HTA agencies is being promoted, as shown through the organization of the first meeting on benchmarking of drug assessment held in Barcelona in June this year (41).

Methods used for HTA have been gaining sophistication over time, in parallel to the evolving evolution of the methods for this discipline. The first methods used were systematic reviews, taking into account the quality of the literature; later studies using meta-analysis, decision analysis, and cost-effectiveness analysis were carried out. Although qualitative and quantitative methods, or a mix of both, have been used progressively in the assessments. Context considerations have been always taken into account, more or less in a constantly progressive way.

To date, there are seven HTA agencies in Spain. This fact has raised some voices claiming that HTA threatens efficiency and equity in the Spanish territory. The former is not a threat anymore. Although at the beginning of the introduction of HTA in Spain these agencies were not very coordinated, lately they are becoming more and more coordinated in the work they are carrying out and are starting to be specialized in different topics. Additionally, the availability of their own agencies in those more developed regions where new health technologies are being requested allows a quick identification of those technologies that need assessment. These agencies assess the technology and share the results with other regions, while being sensitive to the political health and healthcare priorities of the region.

Claims on threats to equity should be faced. Although regulations to link the introduction and public coverage of health technologies exists at the national level, there is not yet a formal procedure to update systematically, and on an ad hoc basis, the lists of procedures to be covered at the national level. The devolution on all healthcare matters to autonomous regions is also a limitation to the guarantee that all technologies are covered and used equally in the Spanish territory. It may be the case that some regions, without a formal process to assess technologies, introduce technology on some basis other than HTA criteria, putting pressures to other regions to adopt this technology. Therefore, although regulatory support at the national level is available (22), mechanisms to enforce the implementation of this regulation should be put in place.

Another important step being promoted in Spain is the development of a methodology to identify and assess obsolete technologies to recommend their withdrawal from public coverage (i.e., disinvestment). This project is being led by two agencies, Avalia-t and Osteba, with the collaboration of other Spanish agencies. The results of this ongoing, and almost finished, project should also be seriously taken into account by the Central Ministry of Health. The results should be included in any procedure that may be established to enforce the regulation regarding introduction of new technologies with public coverage. Being a national health system, with limited resources, one way to promote the introduction of high value innovations is to withdraw those health technologies that are not of high value in clinical practice.

Other important actions have been placed and coordinated at the macro-level, such us a network to identify emerging technologies. Since 2000, Osteba is leading "Sortek," a program that is specifically oriented toward the identification and early assessment of emerging technologies. This initiative has been trying to expand to all Spanish territory, developing a central information system for emerging technologies under the umbrella of the National Quality Plan. This is a very strategic action that can help national and regional governments to predict and proactively plan future investments in health technology.

For hospitals, especially teaching hospitals, the availability of such information is crucial. Here, there is a new area of action that is starting to be promoted by the Spanish agencies, that is, the decentralization of HTA to hospitals. Health technologies, especially high tech and costly drugs, are mainly introduced in Spain through hospitals. Therefore, there should be a strong and coordinated link between those hospitals and the HTA agency in the region, or at the central level. These links will allow agencies to enforce and implement their recommendations at the meso-level, whereas hospitals can help agencies to better assess health technologies adding local considerations to macro-level assessments. Nevertheless, HTA in hospitals should be seen as necessary in its own right. Although criteria used to assess health technologies are the same as at macro-level, the weight given to these criteria in the overall assessment and in the final recommendations are different from the ones at macro-level (e.g., safety and impact in organization are more considered at the 
hospital level than cost-effectiveness, which is emphasized at the macro-level) (8).

Hospital HTA can also have different priorities from the ones at macro-level. Short-term investments, in new medical and or surgical procedures and medical devices and equipment, mandate the agenda of hospital HTA. Additionally, a sound proactive plan (versus reactively driven by physicians) for emerging and new health technologies needs the use of HTA criteria in the medium- and long-term strategic plan for technology (42). Finally, it is worth mentioning that hospitals, especially high technology teaching hospitals, have an important position in the creation and development of ideas that will translate into new products and procedures $(\mathrm{R} \& \mathrm{D}+\mathrm{i})$. HTA units in hospitals can contribute to assessing the probability of success when a new technology reaches the market. Some initiatives in this area are currently being developed abroad through partnerships between private and public institutions (37) or as research projects (32). At the central level, Spain has recently created the Ministry for Innovation and Technologies. All the healthcare research funds and programs as well as the central agency for HTA (AETS), have been transferred to this new Ministry. This creates more opportunities to expand the use of HTA to the beginning of the life cycle of a technology. HTA can therefore become more of the valorization step of any healthcare product.

Spanish agencies have been very active nationally and internationally. As mentioned, CAHTA and Osteba were founding members of INAHTA, with Osteba holding its presidency for 3 years and now in its board of directors. Osteba has also been a founding member of EUROSCAN, currently holding its chairmanship. Professionals from CAHTA have also been long-time members of the Board of Directors of ISTAHC, holding its presidency for 1 year and then being the president during the creation of the new society and now holding the elected presidency of the HTAi Society. Additionally, all of the Spanish agencies have been very active participating in international HTA projects. Therefore, the commitment of Spanish agencies to HTA, and its community, is very high.

The impact of HTA in the design of health policies and clinical practice has varied since its introduction in Spain as well as among regions. The influence of HTA has depended of the political party governing the autonomous region, as well as its priorities in health and health care. Therefore, the influence of HTA on policies has not followed a homogeneous trend toward increase over time, although activities from HTA agencies/units in fact have been rising over time. The promotion of HTA from the central Ministry of Health through the "Quality Plan for the NHS" has greatly helped the implementation and awareness of HTA at all the levels of the healthcare system (macro, meso, and micro). Nowadays, clinicians also compete for research funds in the HTA call for research. Educational courses at the National Scientific Societies level regarding HTA and EBM are also being carried out more and more.
Although as said at the beginning of the discussion, Spain is in its maturity regarding HTA, an essential piece is lacking: there is a need for a stronger link between the HTA of the regional agencies and the procedures and recommendations and central high level policy decision making at the Ministry of Health. In addition, HTA needs to be linked so well that it is not susceptible to political changes, such as to the party in power.

\section{CONTACT INFORMATION}

Laura Sampietro-Colom, MD, PhD (lsampiet@clinic.ub. es), Deputy Director, Innovation Directorate, Hospital Clinic, Villaroel 170, 080036 Barcelona, Spain

José Asua, MD, PhD (jasua-osteba@ej-gv.es), Head, Osteba-Basque Office for HTA, Department of HealthBasque Country, Donostia-San Sebastian, 1, 01010 VitoriaGasteiz (Basque Country), Spain

Eduardo Briones, MD, MSc (briones@cica.es), Chief, Department of Healthcare Quality and Documentation, Valme University Hospital. Andalusian Health Service. Av. Bellavista s/n, Sevilla, Spain, 41003

Jordi M. Gol, MD (jmgol@isciii.es), Director de Programas, Agencia de Evaluación de Tecnologias Sanitarias (AETS), Insituto de Salud "Carlos III," Sinesio Delgado 4, 28029 Madrid, Spain

AuNETS Group: Antonio Sarria-Santamera (Spanish Agency for Health Technology Assessment); Pedro Serrano (Health Technology Assessment Unit of Canary Island); Sandra Flores (Andalusian Agency for Health Technology Assessment); Elena Andradas (Health Technology Assessment Unit of Madrid, Laín Entralgo Agency); Teresa Cerdá (Galician Agency for Health Technology Assessment); Oriol de Sola-Morales (Catalan Agency for Health Technology Assessment and Research)

\section{REFERENCES}

1. Agència d'Avaluació de Tecnologia i Recerca Mèdiques (AATRM). Universitat Oberta de Catalunya (UOC). Avaluació en serveis sanitaris [curs virtual de 90 hores a través d'internet]. Barcelona: http://www.aatrm.net (accessed October 31, 2008).

2. Agència d'Avaluació de Tecnologia i Recerca Mèdiques (AATRM). Universitat Oberta de Catalunya (UOC). Habilitats informacionals en ciències de la salut[curs virtual de 60 hores a través d'internet]. Barcelona (Iniciat any 2002). http:// www.aatrm.net (accessed October 31, 2008).

3. Agencia de Evaluación de Tecnologías Sanitarias de Andalucía. Gobierno de España. Actualización de la Guía para la Adquisición de Nuevas Tecnologías (GANT). Informes, estudios e Investigación. 2007. Barcelona: Ministerio de Sanidad y Consumo.

4. Agencia de Evaluación de Tecnologías Sanitarias. INAHTA Newsletter. This is AETS. Stockholm: INAHTA; 1997.

5. Artís M, Surinyach J, Royuela V, Vayá E. L'aportació del sector sanitari a l'economia catalana. http://www.caixacatalunya. 
es/caiaxcat/ccpublic/particulars/publica/pdf/esti05.pdf (accessed August 13, 2008).

6. Aunets.es. AUnETS Agencias y Unidades de Evaluación de Tecnologías Sanitarias. http://aunets.isciii.es/web/guest/home (accessed September 2008).

7. Banta D. Introduction to the EUR-ASSESS Report. Int J Technol Assess Health Care. 1997;13:133-143.

8. Cicchetti A, Marchetti M, Di Bidino R, Corio M. Hospital based health technology assessment world-wide survey. 2008.

9. Clavero Salvador J. Seminario sobre evaluación de tecnología sanitaria. Sevilla: Consejería de Salud; 1993.

10. Consellería de Sanidade. Xunta de Galicia. Orde do 28 de novembro, pola que se regula o procedemento para a incorporación de técnicas, tecnoloxías ou procedementos á carteira de servizos do sistema sanitario público de Galicia. Santiago de Compostela: Diario Oficial de Galicia (DOG); núm. 238, de 11/12/2007. Barcelona: Consellería de Sanidade; p 19507.

11. Consellería de Sanidade. Xunta de Galicia. Orde do 7 de xullo, pola que se establece o procedemento de incorporación ó Servicio Galego de Saúde de novos procedementos, técnicas e outros medios sanitarios. Santiago de Compostela: Diario Oficial de Galicia (DOG); núm. 139, de 18/07/2003. Barcelona: Consellería de Sanidade.

12. Ecole Polytecnique Federale de Laussanne et l'Institut Suisse de la Sante Publique et des Hopitaux (ISH/SKI). Cours d'Evaluation des Tecnologies Medicales. 10-14 September 1990 Laussanne (Suisse).

13. Escribano S. Una de cada diez familias contrata un seguro sanitario en la provincia. [Monography on the Internet]. http:// www.diarioinformacion.com/secciones (accessed November 14, 2008).

14. Eunethta.net. European Network of Agencies for Health Technology Assessment. http://www.eunethta.net (accessed 2008)

15. EuroScan.uk. International Information Network on New and emerging Health Technologies: EuroScan. http://www. euroscan.bham.ac.uk (accessed May 4, 2008).

16. Fenin.org. Federación Española de Empresas Sanitarias. Fundación Tecnología y Salud. http://www.fenin.org/fundaciontecnologia-y-salud.html (accessed September 20, 2008).

17. Fundació Clínic.org. Fundació Clínic per a la Recerca Biomèdica. http://www.fundacioclinic.org (accessed September 12, 2008).

18. Generalitat de Catalunya. Departament de Sanitat i Seguretat Social. Ordre de 15 de juliol de 1984, per la qual es crea la Comissió Assessora d'Alta Tecnologia Mèdica. DOGC núm. 460; 10/8/.4891 Barcelona: Generalitat de Catalunya.

19. Generalitat de Catalunya. Departament de Sanitat i Seguretat Social. Decret 27/1991, de reestructuració del Departament de Sanitat i Seguretat Social. DOGC núm. 1411; 25/2/.1991 Barcelona: Generalitat de Catalunya.

20. Genesis.es. Grupo de Evaluación de Novedades, EStandarización e Investigación en Selección de medicamentos. GENESIS. Sociedad Española de Farmacia Hospitalaria. http://genesis.sefh.es (accessed June 2, 2008).

21. Gobierno de España. Ministerio de la Presidencia. Resolución de 25 de julio, del Instituto de Salud Carlos III, por la que se convocan acciones especiales para la difusión en investigación sobre evidencia científica y en evaluación de tecnologías sanitarias dentro del programa de recursos humanos y difusión de la investigación. Madrid: Boletín Oficial del Estado (BOE); núm. 205, de 27/8/2007.

22. Gobierno de España. Ministerio de la Presidencia. Ley 16/2003, de 28 de mayo, de cohesión y calidad del Sistema Nacional de Salud. Madrid: Boletín Oficial del Estado (BOE);núm.128, de 29/5/2003.

23. Gobierno de España. Ministerio de la Presidencia. Ley 29/2006, de 26 de julio, de garantías y uso racional de los medicamentos y productos sanitarios. Madrid: Boletín Oficial de Estado (BOE); núm 178, de 27/07/2006.

24. Gobierno de España. Ministerio de la Presidencia. Real Decreto 63/1995, de 20 de enero, sobre ordenación de prestaciones sanitarias del Sistema Nacional de Salud. Madrid: Boletín Oficial de Estado (BOE); núm. 35, de 10/2/1995.

25. Gobierno de España. Ministerio de la Presidencia. Resolución, de 22 de marzo, del Instituto de Salud Carlos III, por la que se convocan ayudas del programa de Promoción de la Investigación Biomédica y en Ciencias de la Salud para la realización de estudios de investigaciones sobre evaluación de tecnologías sanitarias e investigación en servicios de salud en el marco del Plan Nacional I+D+I 2004-2007, durante el año 2007. Madrid: Boletín Oficial del Estado (BOE); núm. 80, de $3 / 4 / 2007$.

26. Gobierno de España. Ministerio de la Presidencia, inisterio de la Presidencia. Real decreto 1030/2006, de 15 de septiembre, por la que se establece la cartera de servicios comunes del Sistema Nacional de Salud y el procedimiento para su actualización. Madrid: Boletín Oficial del Estado (BOE); núm. 222, de 16/9/2006.

27. Granados A, Almazan C, Teres J, et al. The assessment of medical technology and reimbursement policy: The case of biliary lithotripsy. In: Proceedings of the 13th Annual Meeting of ISTAHC, May 23-26, 1993. Sorrento, Italy.

28. Granados A, Sampietro-Colom L, Asua J, Conde J, VazquezAlbertino R. Health technology assessment in Spain. Int J Technol Assess Health Care. 2000;16:532-559.

29. Hailey D, Marshall D, Sampietro-Colom L, et al. International collaboration in health technology assessment: a study of technologies used in management of osteoporosis. Health Policy. 1998;43:233-241.

30. Health Technology Assessment International (HTAi). HTA for evidence based public health. In: Proceedings of the IV Annual Meeting of Health Technology Assessment International (HTAi), Barcelona, June 17-20, 2007.

31. HTAi.org. International Society for Health Technology Assessment. http://www.htai.org (accessed October 14, 2008).

32. Inno-hta.eu. HTA-methodology for innovative health technologies (Inno-HTA). http://www.inno-hta.eu (accessed August 12, 2008).

33. International Society for Technology Assessment in Health Care (ISTAHC). In: Proceedings of the XIII Annual Meeting of ISTAHC, Barcelona, May 25-28, 1997.

34. Jonson E, Banta D, Henshall CH, Sampietro-Colom L. Summary report of the ECHTA/ECAHI Project. Int J Technol Assess Health Care. 2008;18:218-232.

35. Jovell AJ, Aymerich M. Evidencia científica y toma de decisiones en sanidad. Barcelona: Acadèmia de Ciències Mèdiques de Catalunya i Balears; 1999.

36. Junta de Andalucía. Gobierno de España. Decreto 318/1996, de 2 de Julio, por el que se crea la Agencia de Evaluación 
de tecnologías Sanitarias de Andalucía (AETSA). Sevilla: Boletín Oficial de la Junta de Andalucía (BOJA); núm. 77, de 06/07/1996. p 7481.

37. Match.uk. Multidisciplinary Assessment of Technology Centre for Healthcare. MATCH. http://match.ac.uk (accessed August 12, 2008).

38. Ministerio de Sanidad y Consumo.es. Plan de Calidad para el Sistema Nacional de Salud. http://www.msc.es/organizacion/ sns/planCalidadSNS/ (accessed September 13, 2008).

39. Plaza Piñol F. From single to multiple stakeholders: new challenges for market access. En el curso Clinical Trial Strategy and regulatory Approval. SIMS Biotech Executive Programme. Module IV. July 3, 2008.

40. Sampietro-Colom L GA. Health technology assessment of nonionic contrast agents. Catalan Office for Health Technology Assessment (COHTA). Barcelona: Catalonia Ministry of Health; 1993.

41. Sampietro-Colom L. I Meeting on benchmarking of assessment of drugs. Barcelona: September 25-26, 2008.
42. Sampietro-Colom L, Oliva G, Espallargues M, Almazán C, Estrada D, Granados A. Evaluación de tecnología médica en el ámbito hospitalario. Aplicación al diagnóstico por la imagen. Todo Hospital. 2003;200:191198.

43. Sarría-Santamera A. Evaluación de Tecnologías Sanitarias. En Jornadas Claves de futuro en la colaboración industria y agencias de evaluación de tecnologías sanitarias en un mercado global. Madrid: Escuela Nacional de Sanidad, 12 de Noviembre 2007.

44. Szczepura A Kankaanpää J. Interests in health care technology assessment (HCTA) and HCTA training needs in eight European countries: COMETT-ASSESS. Soc Sci Med. 1994;38:1679-1688.

45. World Health Organization Regional Office for Europe. European Observatory on Health Systems and Policies. WHO European Centre for Health Policy. http://www.euro.who. int/observatory/CtryInfo/CtryInfoRes?COUNTRY = SPA\& CtryInputSubmit $=($ accessed 2008). 